\title{
Erratum to: The Study of the Dispersity of Gold Organosols with the Use of $\mathrm{Au}-\mathrm{AOT}$ Composite Films
}

\author{
A. N. Kolodin ${ }^{a}, *$, I. V. Korostova ${ }^{a}$, E. A. Maksimovskiy ${ }^{a}$, A. T. Arymbaeva ${ }^{a}$, and A. I. Bulavchenko ${ }^{a}$ \\ ${ }^{a}$ Nikolaev Institute of Inorganic Chemistry, Siberian Branch, Russian Academy of Sciences, Novosibirsk, 630090 Russia \\ *e-mail: kolodin@niic.nsc.ru \\ Submitted October 2, 2020; accepted for publication October 2, 2020
}

DOI: $10.1134 / \mathrm{S} 1061933 \mathrm{X} 20330017$

In the title of the article and the page headers, Gold Aerosols should read Gold Organosols.

The original article can be found online at https://doi.org/10.1134/S1061933X20050099 